\title{
Forest Fire Susceptibility Mapping Using Analytical Hierarchy Process Approach for Chandoli National Park of Maharashtra, India
}

Shobha N Lohar ( $\sim$ shobhagis123@gmail.com )

Shivaji University

Sachin S Panhalkar

Shivaji University

Abhijit S Patil

Shivaji University

\section{Research}

Keywords: Forest Fire Susceptibility, Analytical Hierarchy Process, Past Burn Area, Chandoli National Park, GIS

Posted Date: June 22nd, 2020

DOI: https://doi.org/10.21203/rs.3.rs-36559/v1

License: (9) This work is licensed under a Creative Commons Attribution 4.0 International License. Read Full License 


\title{
Forest Fire Susceptibility Mapping Using Analytical Hierarchy Process Approach for Chandoli National Park of Maharashtra, India
}

\author{
1) Shobha Lohar \\ Research Student, \\ Department of Geography, Shivaji University Kolhapur, Maharashtra \\ Email- shobhagis123@gmail.com
}

2) S. S. Panhalkar

Professor,

Department of Geography, Shivaji University, Kolhapur, Maharashtra

Email-panhalkarsachin@gmail.com

3) Abhijit S. Patil

Assistant Professor,

Department of Geography, Shivaji University, Kolhapur, Maharashtra

Email-abhijitpatil8893@gmail.com 


\section{Declarations}

\section{Availability of data and materials}

Landsat 8 (OLI/TIRS), Google Image etc.

\section{Competing interests}

Not Applicable

\section{Funding}

Not Applicable

\section{Authors' contributions}

All authors have contributed equally

\section{Acknowledgments}

I am grateful to office of the Chief Conservator of Forests (Territorial) Kolhapur for gave me research permission in restricted study area. My sincere thanks to Dr.Ben V Clement (Chief Conservator of Forest,Kolhapur Division) and Dr.Vinita Vyas (Deputy Director, Shyadri Tiger Reserve project Kolhapur,Karad office) for providing the impetus and stimulus to carry out this research work. 


\title{
Forest Fire Susceptibility Mapping Using Analytical Hierarchy Process Approach for Chandoli National Park of Maharashtra, India
}

\begin{abstract}
The forest fire management starts with identifying fire potential areas. This study suggests a new approach based on Geographic Information Systems (GIS), Remote Sensing (RS), and Analytical Hierarchy Process (AHP) to map forest fire susceptibility of Chandoli National Park of Maharashtra. Influencing factors like past burnt area, Land Surface Temperature (LST), forest type, agriculture area, road network, and the vicinity of settlements taken into consideration. All variables assigned a weight based on their impact on the fire susceptibility. The final map categorized, ranging from very high to very low, into five fire susceptible regions. The result indicated that $12.99 \%$ (6506.89 ha) land area of the study region came in a very high susceptible region, while $18.70 \%$ (9361.10 ha) of high. The forest fire susceptibility map shows that $12.26 \%, 44.42 \%, 11.61 \%$ area comes under moderate, low, and very low- susceptible areas, respectively. Afterward, an accuracy assessment carried out with existing records of the forest fire. The mostly very high and high susceptible forest fire region comes where high road density, settlements and agriculture fields dominate. The result reveals that the anthropogenic factors and its activities in the forest region responsible for the frequent forest fire. The unification of remote sensing and the Analytical Hierarchy Process into GIS is beneficial to determining forested areas with high fire susceptibility and also to plan forest management after a forest fire.
\end{abstract}

KEYWORDS: Forest Fire Susceptibility, Analytical Hierarchy Process, Past Burn Area, Chandoli National Park, GIS.

\section{INTRODUCTION}

Forest fires are one of the significant natural and human-made hazards which evince effects on species of biodiversity include wildlife, environment, and also on humans (Buyyani et al. 2014). It increases the intensity of suppression in the forest, which is one of the richest biodiversity areas in the natural environment (Carvalho et al. 2011). Despite the use of advanced technology to prevent forest fires, an ecological problem remains to threaten the

forests. Forest fire annually affects thousands of hectares of areas and cause dramatic changes in the forest ecosystem (Goldammer et al. 2001).

According to FAO (Food and Agriculture Organization, 1986), 'Forest Fire Risk' is the chance of a fire starting as determined by the presence and activity of any causative agent. 
The entire forest fire susceptibility depends on the proportion of available fuel and its sensitivity to burning and on the presence of anthropogenic and natural causes leading to fire inflammation. The natural parameter includes topographic factors (Slope, elevation, and Aspect), biologic factors (vegetation type and density), and the climatic factors (temperature, relative humidity, precipitation, and wind velocity). Human related activities in the forest areas are the anthropogenic factors such as agricultural activities, recreational activities, the existence of forest roads, and settlements. In India, 2-3 \% of the forest area affected annually by the fire, and on average, over 34000 ha forest areas are burnt by fire every year (Thakur et al. 2014). To understand the forest fire effects and ecosystem response is a challenge to researchers and management (Eskandari. 2018). it is not possible to control nature; still, it is possible to map the forest fire susceptibility to reduce the frequency of forest fire. Forest fire zones are locations where the forest fire is likely to start, and from where it easily be spared to other areas. An accurate assessment of forest fire problems and decide on solutions can only be satisfied when a Forest Fire susceptible region is available (Thakur et al. 2014).

The investigation presents the forest fire susceptibility of Chandoli National Park to identify and classify the suitability of zones. The final map will reduce the risk of fire and improve the activities of prevention (Ljubomir et al. 2018). Various works have done on this aspect. Cengiz et al. (2018) have used the AHP approach with 12 anthropogenic and physical variables to analyze the forest fire risk in Turkey. Ljubomir et al. (2018) identified forest fire hazards and to map in the area of municipality Nevesinje, Bosnia, and Herzegovina (located in the south-east part of the Republic of Srpska) by using GIS and AHP model process. The model developed with the aid of 8 criteria and the final map classified into five categories. Eskandari (2017) has presented his research work to perform a model for fire risk in a part of the Hyrcanian forests of Iran. Forest fire risk zonation for Dehradun District, Uttarakhand, has done by Thakur et al. (2014). The prime aim of this research is to find out the forest fire-prone areas and their prioritization.

\section{STUDY AREA}

Chandoli National Park is one of six national parks in Maharashtra, located near the Chandoli Dam between $17^{\circ} 04^{\prime} 00^{\prime \prime} \mathrm{N}$ to $17^{\circ} 19^{\prime} 54^{\prime \prime} \mathrm{N}$ and $73^{\circ} 40^{\prime} 43^{\prime \prime}$ E to $73^{\circ} 53^{\prime} 09^{\prime \prime}$ E (Fig. 1) at the junction of Satara, Kolhapur, Sangli, and Ratnagiri districts. It mainly stretched along the 
crest of the North Sahyadri range of the Western Ghats, between the Koyna and Radhanagri Wildlife sanctuaries. This area was declared a sanctuary on 16 September 1985, later on as National Park on 14th May 2004 (Ekwal 2011). Previously the sanctuary area was 308.86 sq km. After the sanctuary area became National Park, it added ten sq. Km, and now the park has 318.86 sq. Km core area and buffers with $181.72 \mathrm{sq} \mathrm{km}$. The total area is 500.58 sq.km.

\section{RESEARCH METHODOLOGY}

For the present research, the following methodology has been used (Fig.2).

In the present investigation Analytical hierarchy process (AHP) method has been successfully applied for mapping forest fire susceptibility in the study area. The first hierarchy structure defined with variables (Past Burnt Area, Vegetation Types, LST, Road Network, Settlements and Agricultural Area). It uses the multi-level hierarchical structure of criteria and sub-criteria. The AHP method is an ordinal pairwise comparison of all useful criteria in a unique objective (Saaty. 2000). According to the importance given rate to a variable based on a ninepoint scale (Table.1). Quantitative weights assigned the criteria by using an eigenvalue matrix technique. The further process to assign a final weight to criteria, by normalized pairwise matrix method, calculates the list of weights of the factors, later it combined with the attribute map layers to demarcate susceptible region (Kumar et al. 2015).In this way, different elements weighted with a comparable measurement scale.

Finally, the Consistency Ratio (CR) used to check the accuracy of the criteria weight. $\mathrm{CR}$ value is the outcome of the ratio between the values of the indexes CI \{Consistency Index, and an expression shown in Eq. (1) $\}$ and RI \{Random index, an expression is shown in Eq. (2) \}.A random index extracted from the mean RI table (Table.2) based on the number of criteria (n) in the pairwise comparison matrix. Lastly, computed CR of each pairwise comparison matrix, and only those with $\mathrm{CR} \leq 0.1$ had acceptable.

$$
\boldsymbol{C I}=\frac{\lambda \max -N}{(\mathbf{N}-\mathbf{1})}
$$

Where, $\lambda \max =$ Maximum eigenvalue of comparison matrix

$\mathrm{N}=$ Number of variables ( 6 in the study).

$C R=\frac{\mathrm{CI}}{\mathrm{RI}}$

Where $\mathrm{CI}=$ Consistency Ratio $\quad \mathrm{RI}=$ Random Index 


\section{RESULT AND DISCUSSION}

\subsection{GIS layers (Factors affecting forest fire Occurrence)}

For the forest fire susceptibility mapping last five-year past burn area(PBA), Settlements, Road Network, Forest type, Agriculture area, and Land surface temperature (LST), these map layers were generated.

\section{Past Burn Area:}

One of the most famous indices used for mapping burn area is the normalized burn ratio (NBR), which combines the reflectance in the NIR and SWIR bands (See Eq.3). NBR is the most sensitive index to emphasize burned areas and to determine the severity of the burns.

$N B R=\frac{N I R-S W I R}{N I R+S W I R}$

The temporal difference between pre-fire and post-fire NBR to produce an index is the Differenced Normalized Burn Ratio (dNBR) (See Eq.4).

$$
d N B R=N B R \text { pre }- \text { NBR post }
$$

In the present study, pre-fire and post-fire NBR of the last five years (from 2014 to 2018) calculated from Landsat 8 (OLI/TIRS) images(as per data availability) in the peak period of a forest fire, and then pre/post NBR ratios differenced to the mapping burn area. A total of 8.16 sq.km area burned in five years (Fig.3).

\section{Settlements:}

The forest fire and settlements have a positive relationship. In the settlement, lots of human activities can cause burning, which can spread a forest fire \& cause a lot of havoc. Despite the natural fires, anthropogenic is a significant source of forest fire in India. About 95 percent of forest fires are human-made (Biswadip et al. 2010). The visual digitization process extracted settlements in the study area on Google image in ArcGIS (Fig: 4).

\section{Road Network :}


Similar to the village, the road also has enough human activities and vehicle movements, although less than communities. Any physical activity by man or vehicle on the road could cause an unwanted fire. Thus proximity to the road plays a vital role in the chance of fire (Saklani 2008). The road network also digitized by google image in ArcGIS and generated the map (Fig.5).

\section{Forest Type}

The grass and dry vegetation are more susceptible to fire in comparison to moist and evergreen ones. The moisture content of vegetation delays ignition ( Saklani 2008). Open forest with grass this vegetation class generated by a supervised classification technique, which is a vulnerable area to wildfire (Fig.6). For the generation of vegetation map, a combination of field knowledge, expert opinion, supervised classification, and other information obtained from forest departments was utilized.

\section{Agriculture Area}

The human interference frequency leads the forest fire; due to agriculture expansion, loss of habitat of wildlife has seen, and as a result, human-animal conflicts have also increased. The seasonality of cropping pattern, monitoring burning drive to LST and indirect forest fires. The agricultural field also visually digitized on Google image (Fig.7).

\section{Land Surface Temperature (LST)}

The land surface temperature plays a very crucial role in a forest fire; in fact, LST is a driver of wildfire. By using the thermal band of Landsat imageries (Band 10 \& 11), Land surface temperature was calculated (Fig.8). In the first step, the Digital numbers were converted to spectral radiance using radiance rescaling factors provided in the metadata file, by the following formula (See Eq.5).

\section{$L(\lambda)=$ gain $* D N+$ offset}

The second step is to transform the spectral radiance to at-satellite brightness temperature using the thermal constant, by the following formula (See Eq.6).

$\mathrm{T}=\frac{K 2}{\operatorname{Ln}\left(\frac{K 1}{L \lambda}+1\right)}-272.15$ 
Where $\mathrm{T}$ is the at-satellite brightness temperature $(\mathrm{K}) ; \mathrm{K} 1$ and $\mathrm{K} 2$ are calibration constants. For Landsat- 8 TIR, band10 $\mathrm{K} 1$ value is $774.89 \mathrm{~K}$ and $\mathrm{K} 2480.89 \mathrm{~K}$ whereas, band $11 \mathrm{~K} 1$ value 1321.08K and K2 1201.14K (Patil et al. 2018).

The last step is the calculation of land surface temperature (See Eq.7).

$\mathbf{L S T}=\mathbf{B T} / \mathbf{1}+\mathbf{w}^{*}(\mathrm{BT} / \mathrm{p}) * \operatorname{In}(\mathrm{e})$

Where, BT $=$ At satellite Temperature, $\mathrm{w}=$ wavelength of emitted radiance in meters, $\mathrm{p}=$ constant value 14380 and e= emissivity (See Eq. 8).

\section{Land Surface Emissivity}

\subsection{4+ProVeg+0.986}

Where the proportion of vegetation $(\mathrm{Pv})$ can be calculated as (See Eq.9).

\section{Proportion Vegetation $=$}

\section{(NDVI+NDVImin/ NDVImax-NDVImin $)^{2}$}

\subsection{AHP for Forest Fire Susceptibility Mapping}

The mathematical AHP approach used to prepare the map of forest fire susceptibility of Chandoli National Park. The main advantage of the integration of GIS and MCDM is to have unique capabilities that complement each other (Ljubomir. 2018). Thematic layers include Past Burned Areas (2014 to 2018), Road Network, Settlements, Agriculture Areas, Land Surface Temperature (LST), and Open Forest with Grass. By pairwise comparison, the relative position of one criterion concerning all other criteria defined. After the Normalization process, quantitative weights assigned to the criteria. Besides, Consistency Ratio (CR) used to check the accuracy of criteria weight. The summation of these AHP weighted values ranges from 0.094 to 0.543 (fig. 9). This range classified into five categories based on equal interval classification of probable forest fire susceptible regions viz, Very high (0.454-0.543), High (0.364-0.453), Moderate (0.274-0.363), Low (0.184-0.273) and Very Low (0.094-0.183). Very High- susceptible region 
accounts for $12.99 \%$ and High-susceptible for $18.70 \%$ of the study area, respectively (Table.5)

\section{ACCURACY ASSESSMENT OF THE FIRE RISK MAP}

The results of overlaying the map of the actual fire (Burn area in 2019) on the forest fire susceptibility map in Chandoli National Park showed that the burned regions in the study area were highly accordant with the high and very high-hazard classes in the fire susceptibility map (Fig.10). Total $80 \%$ of the burned area located in the high and very high- susceptible classes in the fire susceptibility map. This may be related to the reciprocal relations of the essential active factors in the confines of the actual fire (Eskandari. 2018).

\section{CONCLUSION}

This research focuses on the forest fire susceptibility mapping using GIS and remote sensing in Chandoli National Park. However, this approach shows acceptable accuracy for forest fire susceptibility mapping. The results of this present study revealed that about $12.99 \%$ of the study area (6506.89 ha) a very high- susceptible region, and 18.70\% (9361.10 ha) under a high susceptible region of fire occurrence. It demonstrates that the Chandoli National Park forest exposed to future fires. Prediction of the future fires in the Chandoli National Park forest will be possible using the fire susceptibility map obtained from this study. Therefore, the prevention measures of the future fires occurrence (establishment of scout towers, allocation of the required facilities for firefighting, etc.) should be performed in the high- susceptible area. On behalf of the study, it suggests to the forest department for fire management in the future to enhance the existing conventional fire control system (Kanga. 2017). The integration of the satellite data into GIS is beneficial to determine risky places and to plan forestry management after the fire.

\section{REFERENCES}

Akay A, Erdoğan A (2017) Gis-Based Multi-Criteria Decision Analysis For Forest Fire Risk Mapping. ISPRS Annals of the Photogrammetry, Remote Sensing and Spatial Information Sciences, 4, 25-30. 
Arun Kumar T, Dharmendra S (2014) Forest Fire Risk Zonation Using Geospatial Techniques and Analytic Hierarchy Process in Dehradun District, Uttarakhand, India. Universal Journal of Environmental Research and Technology. 4, 2, 82-89.

Biswadip Gharai, Badrinath KVS \& Murthy MSR (2010) Remote Sensing Application. forest fire monitoring.NRSC.351-362.

Buyyani L, Padmaja B (2014) A Novel Approach for Identification of Forest Fires using Land Surface Temperature Images. IOSR Journal of Computer Engineering. 16,78-83.

Carvalho A C , Carvalho A ,Martins H , Martins H, Marques C , Rocha A ,Borrego V and Miranda A I (2011) Fire Weather Risk Assessment under Climate Change Using a Dynamical Downscaling Approach. Env Model Softw.26, 1123-1133.

Cengiz A, Hasan T, Gürcü A, Bülent S ( 2018) Forest Fire Risk Analysis via Integration of GIS, RS and AHP: The Case of Çanakkale, Turkey. Journal of Human Sciences. 15, 4, 2127 2143.

Chhetri S, Kayastham P(2015).Manifestation of an Analytic Hierarchy Process (AHP) Model on Fire Potential Zonation Mapping in Kathmandu Metropolitan City, Nepal. ISPRS Int. J. GeoInf.4, 400-417.

Ekwal Imam (2011) Use of Geospatial Technology In Evaluating Landscape Cover Type Changes in Chandoli National Park, India. Computational Ecology and Software.1, 2, 95-111.

Eskandari S (2017) A New Approach For Forest Fire Risk Modeling Using Fuzzy AHP and GIS in Hyrcanian Forests of Iran. Arab J Geosci.1-13.

Food and Agriculture Organization report (1986) World and regional reviews Financing Agriculture Development.FAO of United Nation.21-25.

Kanga S, Tripathi G, Suraj Kumar Singh (2017) Forest Fire Hazards Vulnerability and Risk Assessment in Bhajji Forest Range of Himachal Pradesh (India): A Geospatial Approach. JoRSG.8,25-40.

Ljubomir G, Gordana J, Dragoljub J, Miodrag R (2018) GIS Multi-Criteria Analysis for Identifying and Mapping Forest Fire Hazard: Nevesinje, Bosnia and Herzegovina. Technical Gazette. 25,3,891-897.

Patil A and Panhalkar S (2018) Impact of land use Land Cover Change on Land Surface Temperature using Geoinformatic Techniques.IJRAR.5, 4,550-559.

Patil A and Panhalkar S (2019) Analytical Hierarchy Process For Landslide Hazard Zonation of South-Western Ghats of Maharashtra, India. Disaster Advances. 12, 1, 26-33. 
Saaty T (2000) Fundamentals of Decision Making and Priority Theory, 2nd ed., RWS Publications.

Saklani P (2008) Forest Fire Risk Zonation A case study Pauri Garhwal, Uttarakhand, India. A thesis submitted to the International Institute for Geo-information Science and Earth Observation.

Zohreh M, Soleiman M, Limaei (2018) Multiple Criteria Decision Making Approaches For Forest Sustainability (Case Study: Iranian Caspian Forests). Forest Res Eng Int J .2, 114-120. 
Figures

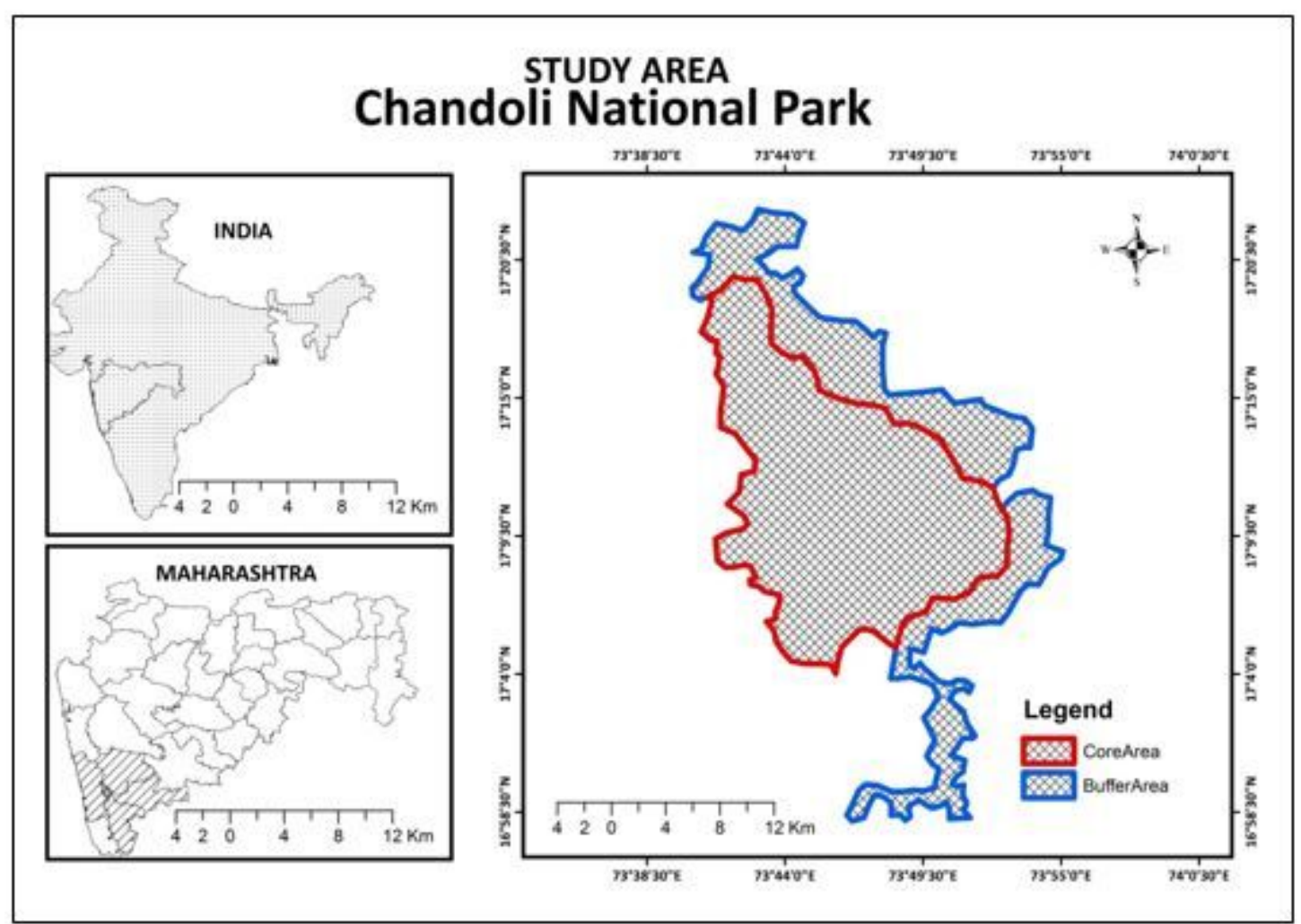

Figure 1

Study Area 


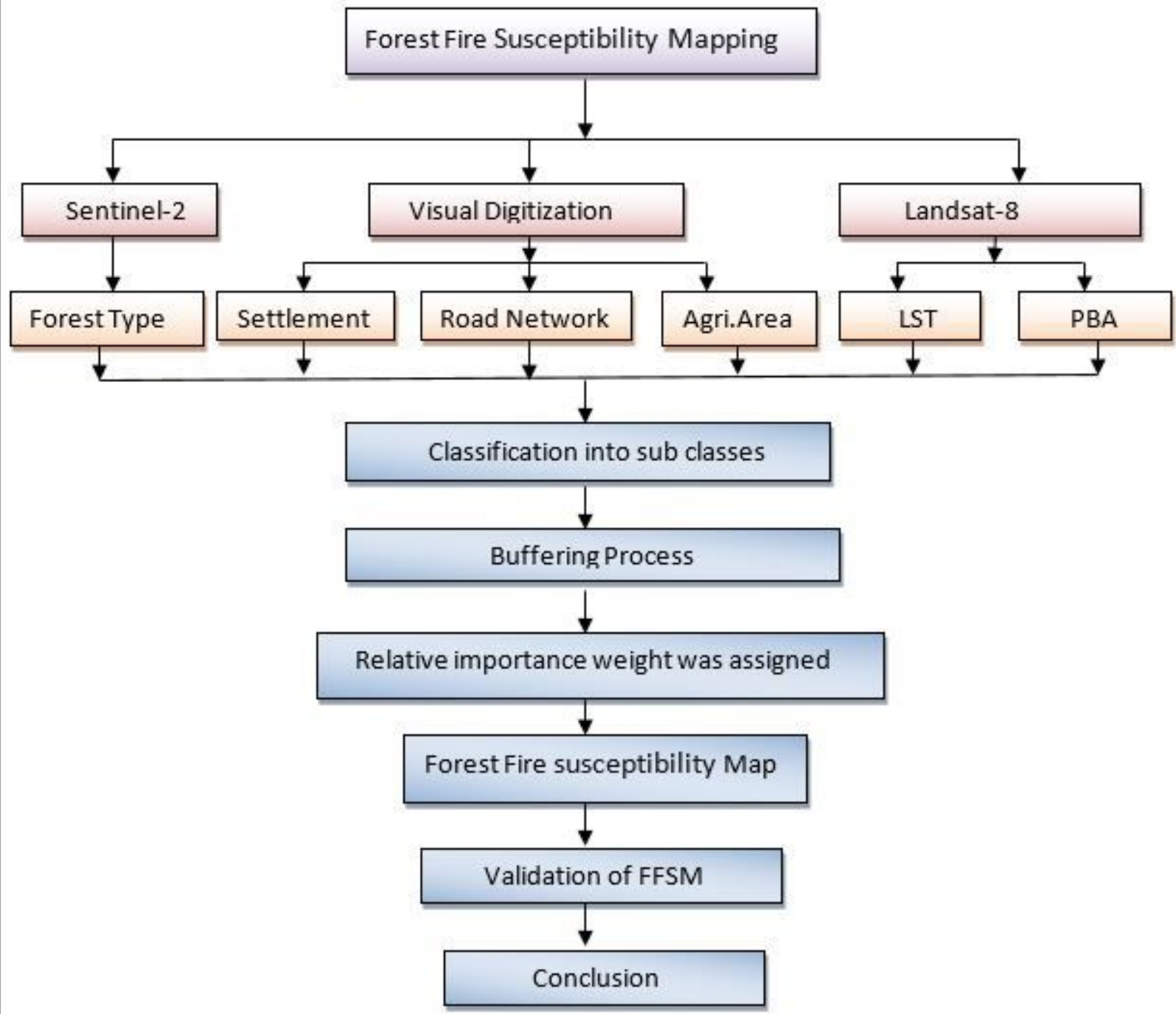

Figure 2

Flow chart of Research Methodology 


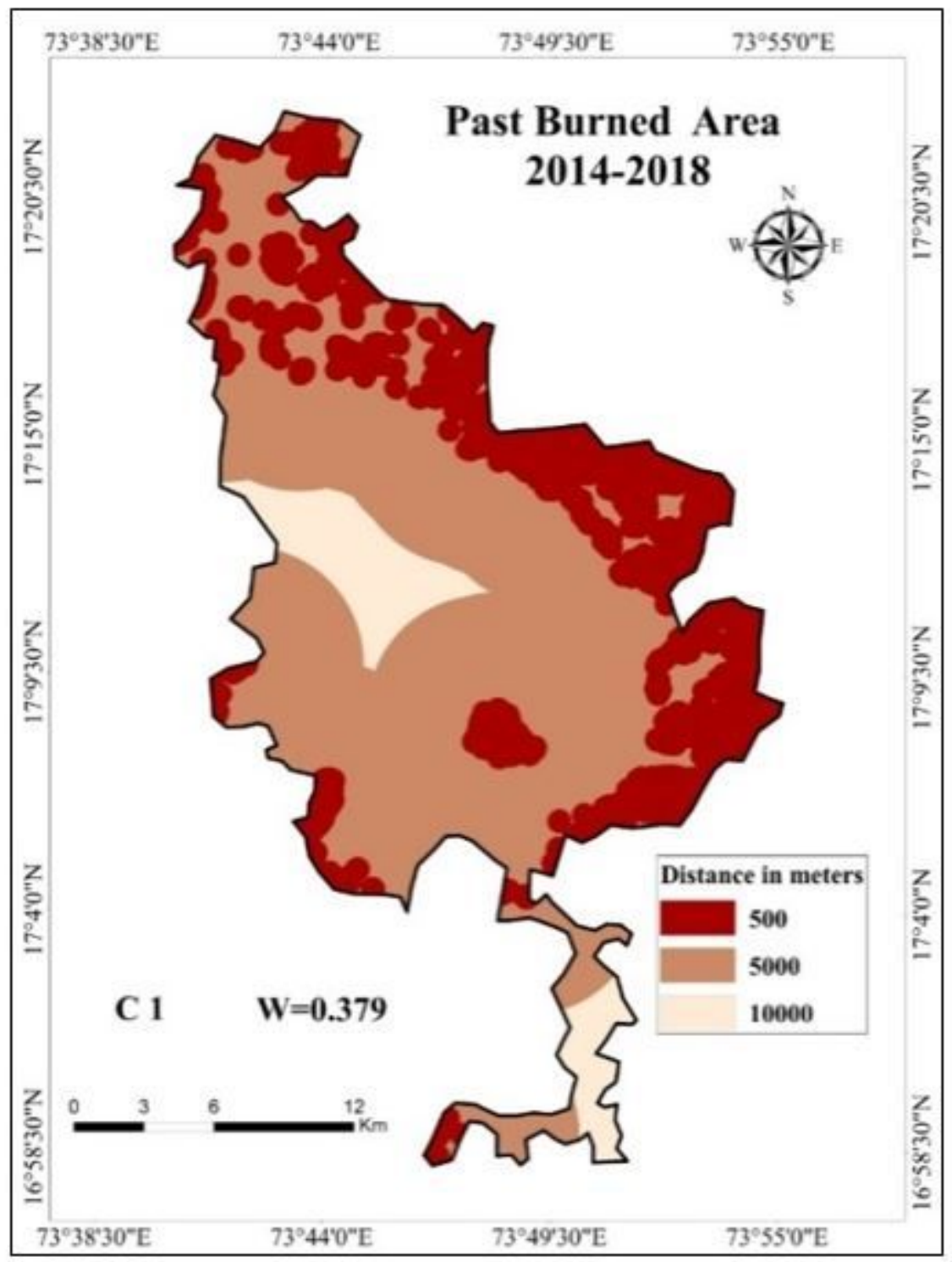

Figure 3

Past Burn Area 


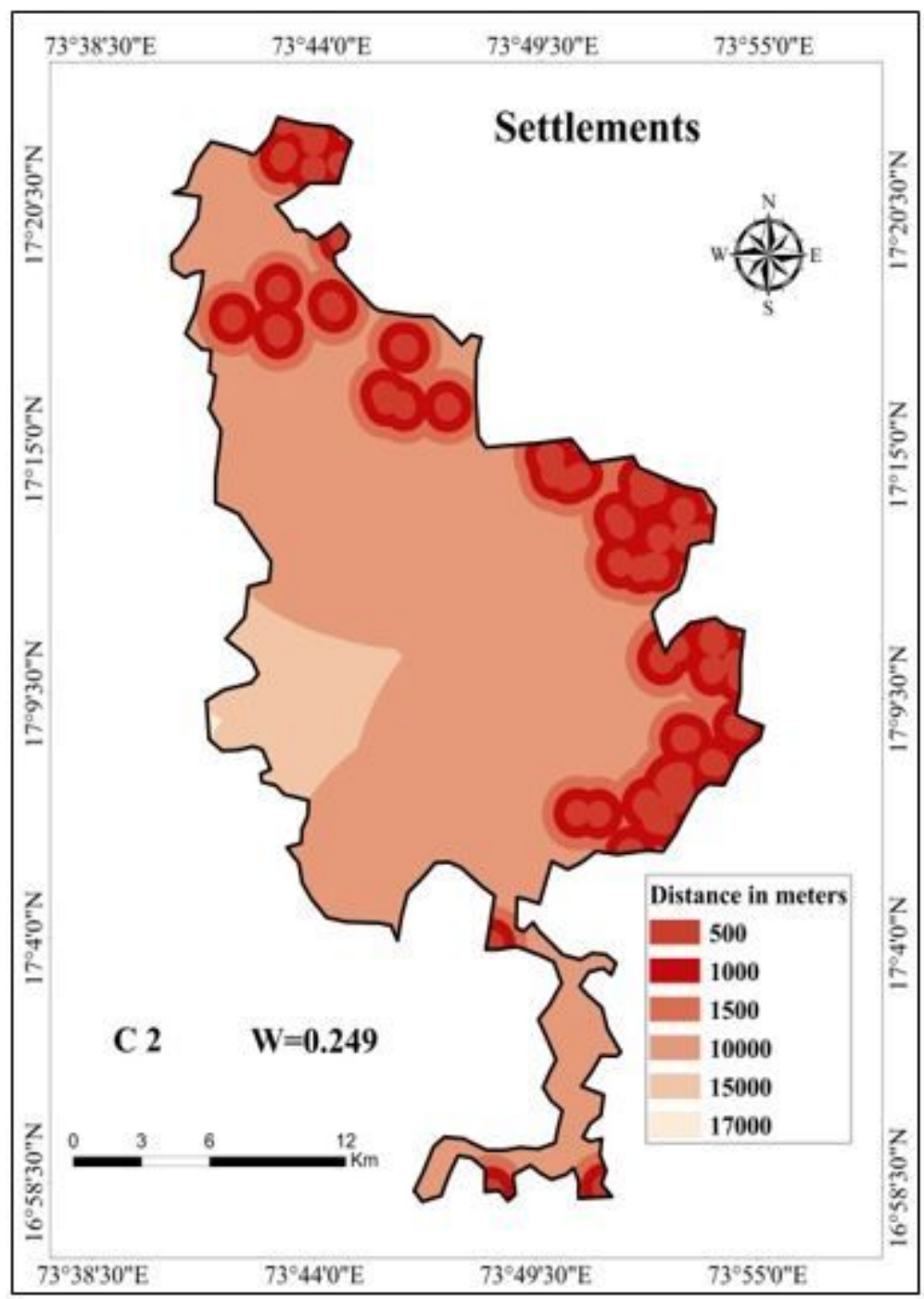

Figure 4

Settlement 


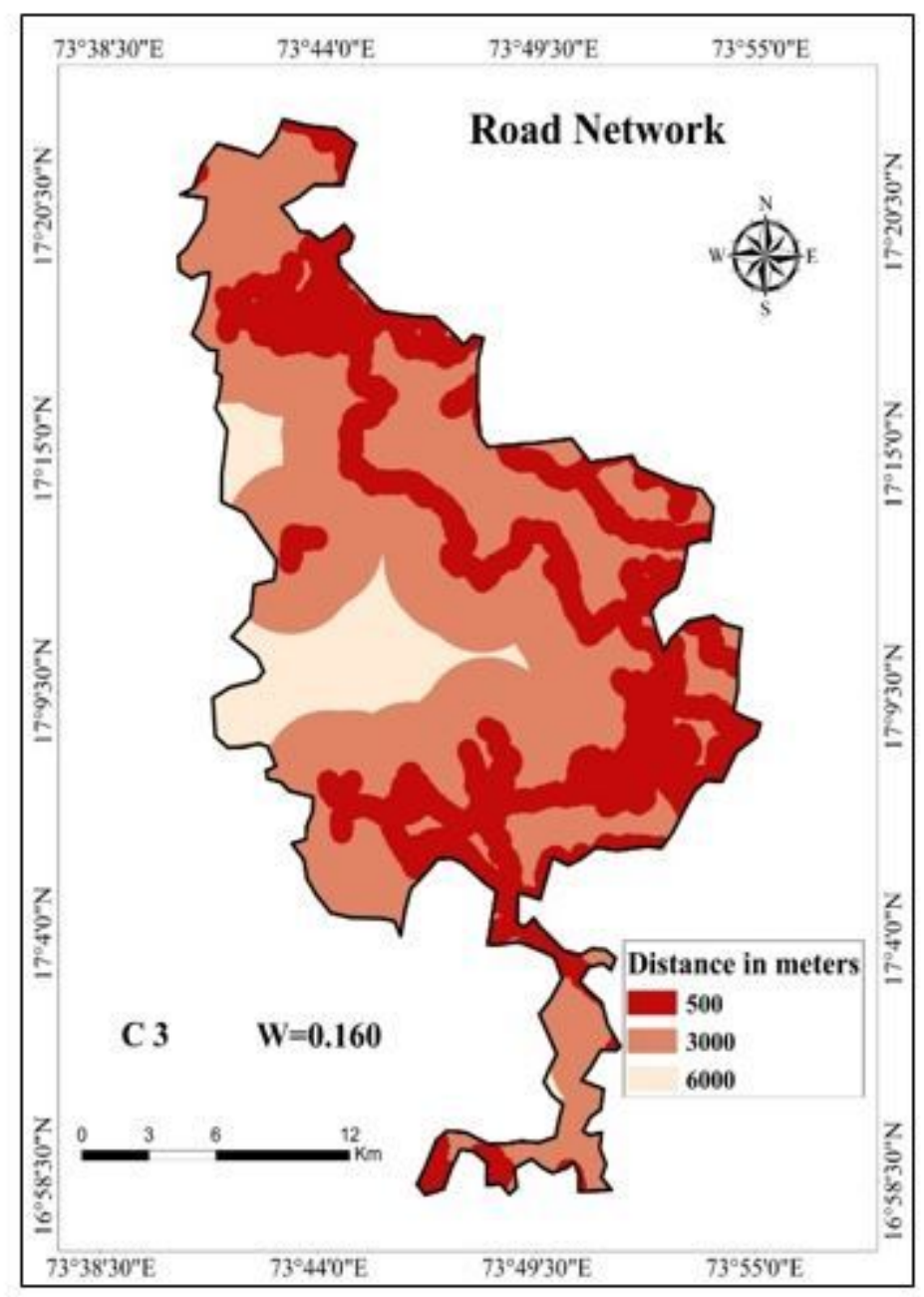

Figure 5

Road Network 


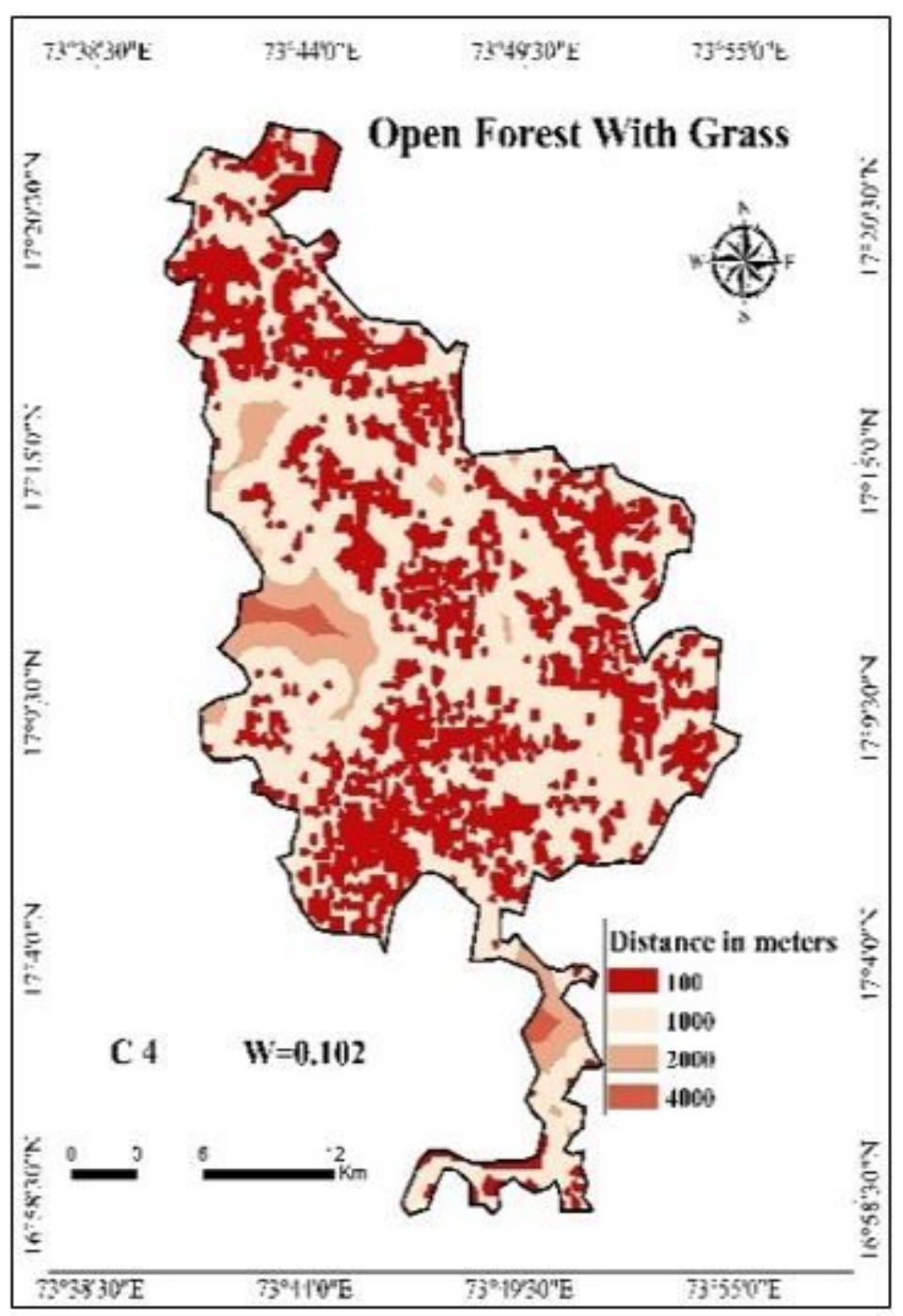

Figure 6

Forest Type 


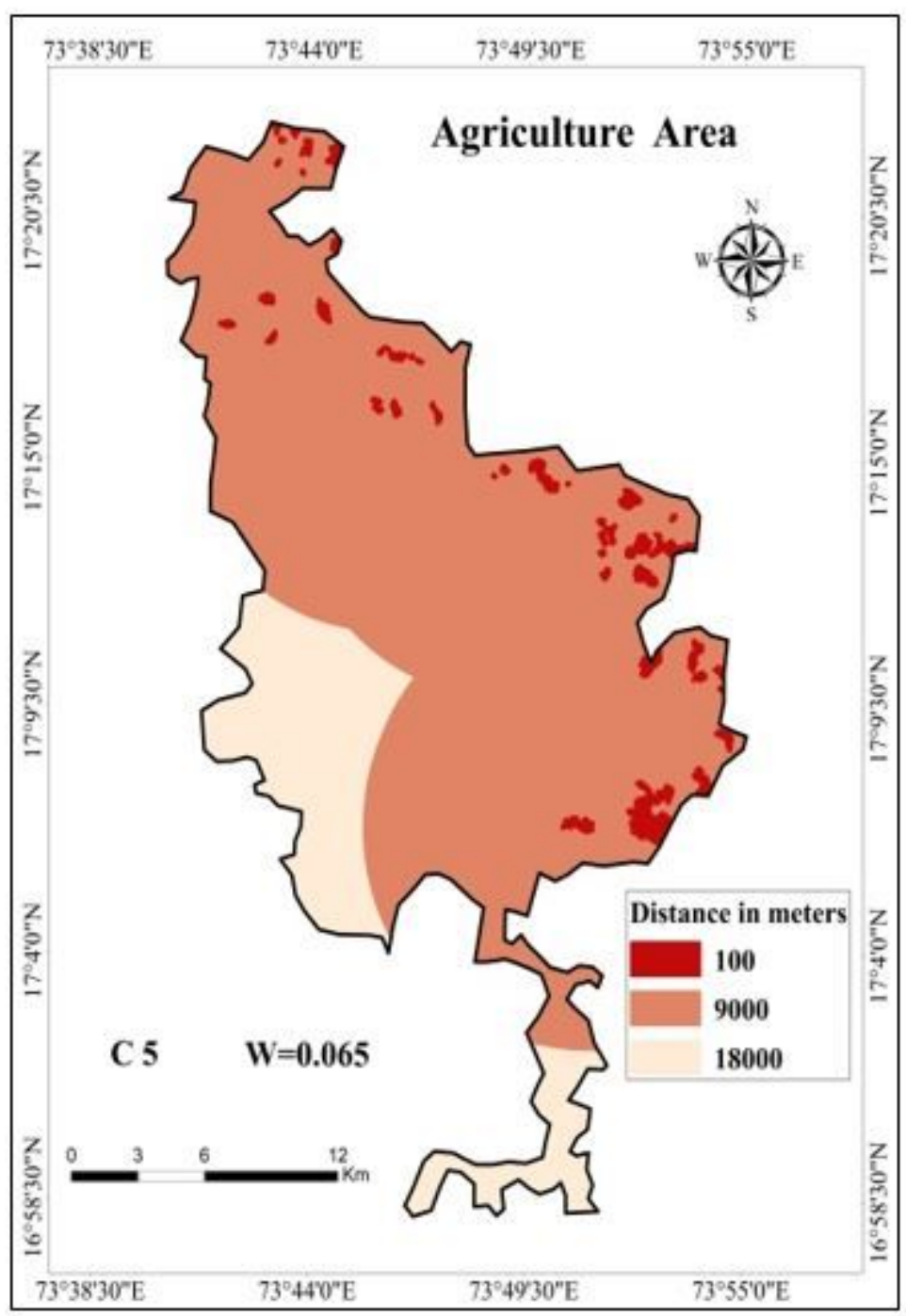

Figure 7

Agriculture Area 


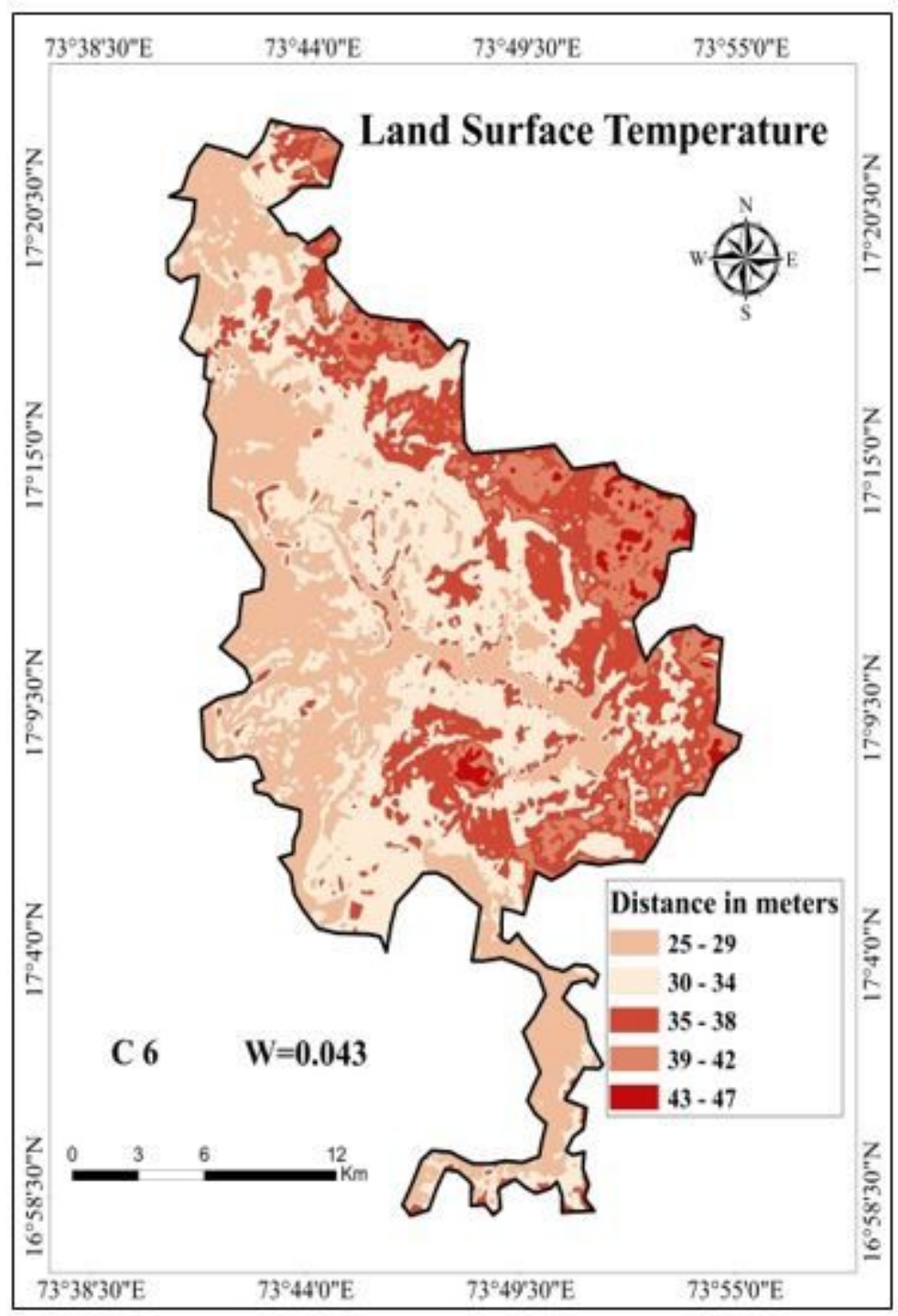

Figure 8

Land Surface Temperature (LST) 


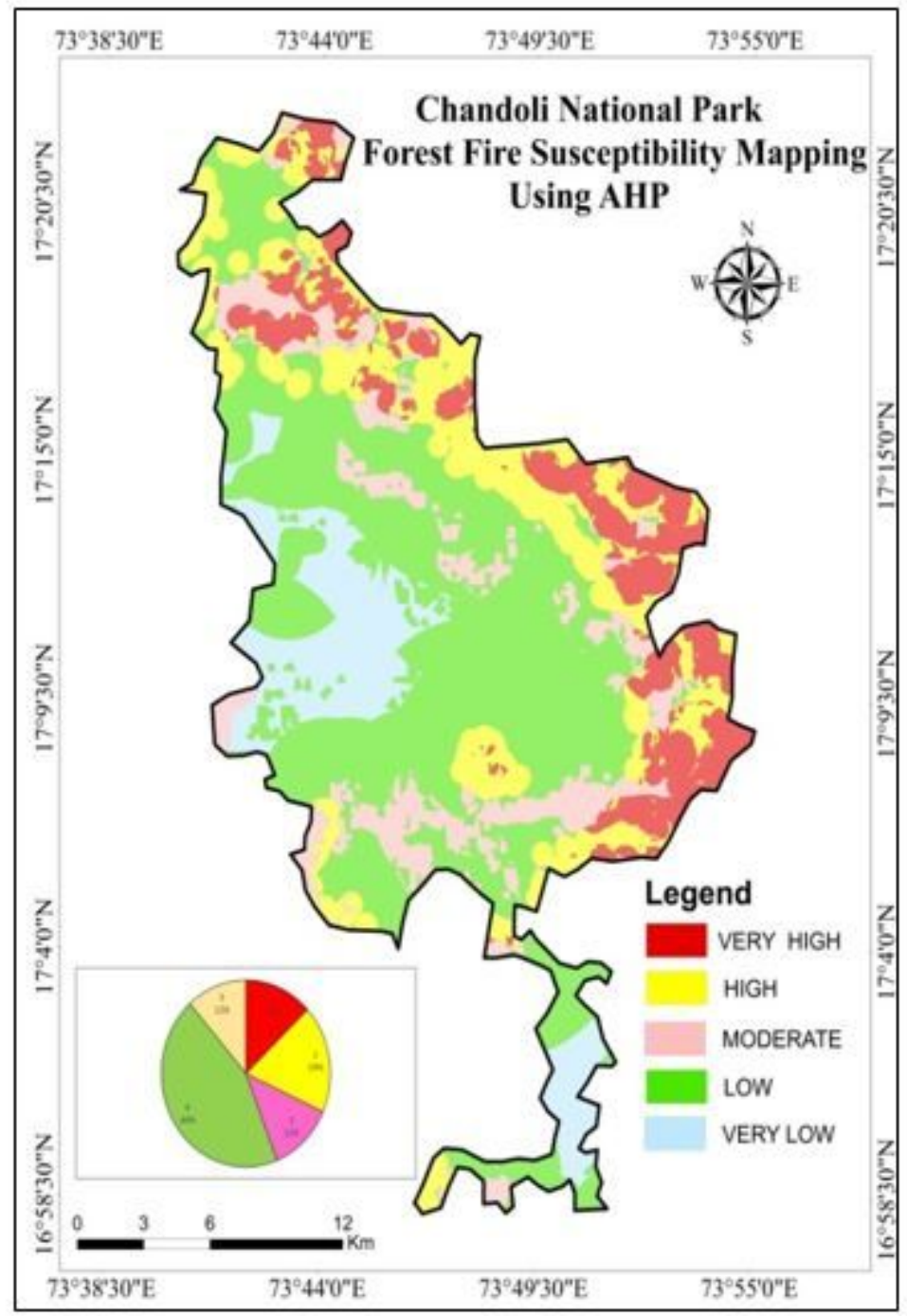

Figure 9

Forest Fire Susceptible Region Map 


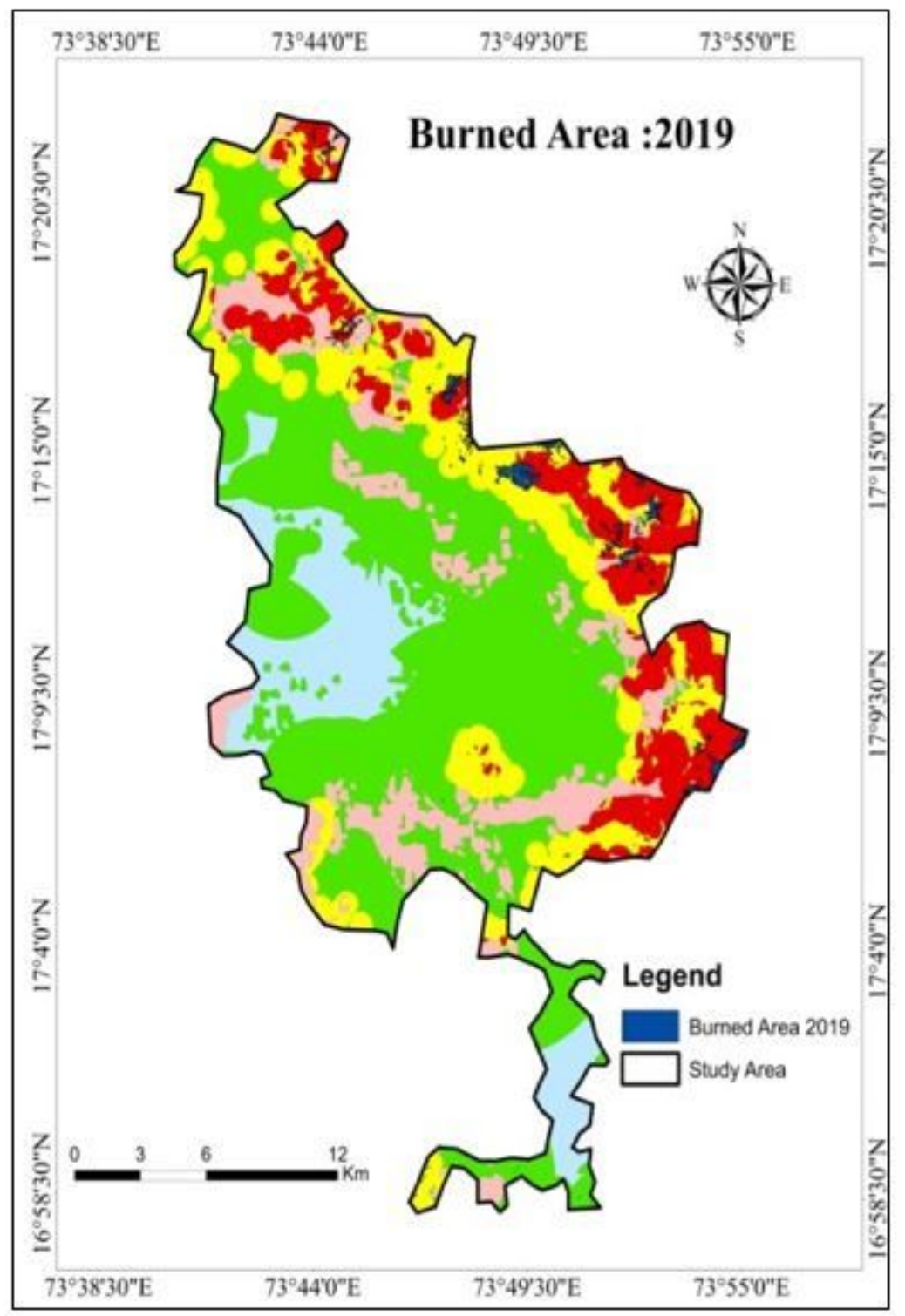

Figure 10

Accuracy Assessment of Fire Susceptibility with existing records 